\title{
Vocational Education Teaching Reform under the Environment of Rich Media
}

\author{
Zheng Jing \\ Shandong Labor Vocational and Technical College
}

\begin{abstract}
Keywords: Rich media; Vocational education; Education propagation mode; Application status quo; Teaching reform practice
\end{abstract}

\begin{abstract}
Rich media environment is vivid, intuitive and informative. It can not only effectively promote the students' quick and firm grasp of knowledge, but also can improve students' practical ability, which has positive significance in improving teaching quality and teaching effect. Now rich media, the new technology, has been widely accepted and applied in many colleges and universities teaching, but in vocational education, rich media is still in the early stages of application, and has not been widely used. There are many problems in practice. This article mainly analyzes how rich media applications in vocational education teaching changes education propagation mode, expounds its present application situation in vocational education teaching, and puts forward vocational education teaching reform practice based on rich media environment.
\end{abstract}

\section{Introduction}

With the development of education teaching and the maturing of education technology, multimedia technology plays a more and more important role in teaching. Multimedia technology applied in teaching is vivid, clear, and changes numerous for brief. In recent years, China's education department pays more attention to the reform progress of vocational education, and the work of vocational education is evitable. Under rich media environment, vocational education teaching reform must make full use of multimedia so as to better promote vocational education in our country for better education benefits. Vocational education teaching has strong practicality and operability, so rich media with concrete, dynamic and vivid practice environment can significantly improve the quality of teaching.

\section{Change analysis in education propagation mode with rich media applications in vocational education teaching}

In the 20th century, school education mainly adopts traditional teaching mode. In the development of the 21st century, people gradually enter the information society, traditional teaching mode has been difficult to meet the need of personal career life development knowledge, and it puts forward new requirements for education teaching reform. The students' learning is a process of accepting new knowledge and new ideas, and this process also has the characteristics of continuity, supportive and exploratory. The focus in traditional teaching is the diligent practice of students, and in the new period, teaching focus needs to be students' understanding and using of knowledge. In this context, rich media provides a good technical support and guarantee for the construction of a new mode of education dissemination. It fully reflects a new spread mode of education thought and education idea. Rich media mainly changes spread education mode in the following aspects:

A. Rich media plays a positive role in promoting students' participation in the process of teaching information transmission and feedback

In traditional teaching, teacher is a controller, while students are the controlled. The relationship between the two is equal, and students are in a passive position. Teaching process is one-way and linear. In rich media environment, the communication, communication and inquiry activity between teachers and students is using one-to-one, one-to-many or many-to-many way. Teachers can be well 
familiar with and understand student's thought and ideas, and in turn, students also can be a very good familiar and understand teachers' ideas and opinions, so that they can better to complete imparting knowledge, creating and sharing, etc. This teaching process has the characteristics of twoway, interaction and nonlinear, and fits the knowledge concept of modern society [1]. In modern society, more and more information constantly appears. We call it information explosion era, and it is impossible to store all the information in a person's mind, so we need to store it in a number of technology platform, and have access to it when needs. In rich media environment, teachers and students will be able to maintain this continuous dialogue relation so as to provide a reliable guarantee to smooth and effective teaching.

B. Rich media changes the representation form of information, which can better meet the diverse needs of the students

With rich media technology support, the representation form of information can be text, video, images or video and other diversified forms, which can better explain, expand, and perform knowledge, and is more conducive to the content, thoughts, feelings and information, etc. for the master of students' knowledge. Rich media environment education propagation mode not only can satisfy visual learners' study need through pictures, graphics, video, but at the same time can also meet sensory learners who like to get information through multi-sensory channels [2]. Through rich media technology, we can create virtual learning environment, physical learning environment and hybrid learning environment for students, and learning style is based on resources or projects, at the same time, can also be based on exploration.

C. Rich media provides students with learning feedback channels, and helps teachers with better learning plan

On the basis of meeting the students' demand of diversification, rich media can effectively improve students' learning adaptability and it can provide teachers and students more convenient way of communication, interaction and communication through network channels. Students can reflect their own specific situation to teachers, and teachers can also provide students timely diagnosis and guidance based on the information, which can effectively improve the traditional education phenomenon lacking of feedback or lag. In rich media environment, teachers get rid of pure spreading knowledge role, but as a manager, mentor and designer, and can better manage and maintain "student-centered" multi-dimensional learning environment, and design studies of students depending on the individual situation of students, and provide better learning platform for students' learning. In addition, this propagation mode also can effectively stimulate students' interest in learning, enables them to be enthusiastic and initiative, and change from slave to learning into study master, who not only can have fun in learning, at the same time also can better promote their own capabilities and the improvement of body and mind development [3]. In general, education system is an open system, and education spread mode is dynamic, organic, and developmental. Therefore it has certain flexibility. Under the environment of rich media, great changes have taken place in the propagation process in the field of education. Traditional teacher-centered mode gradually disappears, and student-centered spread pattern begins to occupy the mainstream in education teaching.

\section{Rich media applications present situation analysis in vocational education teaching}

Rich media includes multimedia ( $2 \mathrm{~d}$ and $3 \mathrm{~d}$ dynamic LI, images and sounds), as well as HTML, Java scripts, Interstitial window clearance, Flash, etc. From the current situation of vocational education teaching in the global range, the application scope of rich media is wider and wider, and application details are perfect especially in Europe and the United States and other developed countries. Its application achieves an unprecedented level. So, rich media teaching has become a major teaching method and teaching tool in the field of professional education. But from the perspective of the actual usage of vocational colleges in our country, the application of rich media teaching is still in its infancy, which is more applied in electrical and electronic, machinery, CNC machine tools science and technology professions, but it is not widely spread. Both for theoretical teaching and practical teaching, rich media has a bridge role. It has changed backward teaching 
mode with blackboard as the main tool, but uses media as a media platform, through objective and vivid virtual reality technology, displays abstract teaching content, provides vivid, lifelike learning environment, unlimited virtual experience in the field of wide range of subjects for students, so on the one hand accelerate and consolidate students' knowledge, provide students with more practical opportunities, on the other hand improve teaching, effectively, and promote the improvement of students operation proficiency [4]. Rich media, therefore, based on $2 \mathrm{~d}$ and $3 \mathrm{~d}$ technology and combined use of image text voice, can create a virtual simulation environment for students, an interactive operation mode which makes environment meet people natural interaction habits so that the students can personally feel and experience knowledge, and actively operate and learn, in order to gain better teaching effect. In addition, through virtual reality technology in rich media, we can build all kinds of virtual laboratories, which not only can completely break traditional laboratory time and space constraints, ensure higher teaching effect, but also can effectively promote teaching cost reduce [5]. For example, in some teachers' equipment machine analysis, remove the components and installation through virtual $3 \mathrm{~d}$ technology, and simulate control system circuit, so that the students can get a more comprehensive and true understanding of teaching content, structure and principle, etc. It has obtained a good practical effect.

\section{Vocational education teaching reform practice analysis based on rich media environment}

A. Provide practice experience for students

Mechanical and electrical professional practice will involve a lot of types of instruments and equipment model. Through computer simulation situation, students can not only observe all kinds of instruments and equipment visual effect from various angles, but also is able to show threedimensional, dynamic operation method of all kinds of instruments and equipment, parts and assembly process. In this process, each screen can provide students with some suggestive voice or text information, which is easier for students to understand. In this way, it can effectively avoid learning boring memorization knowledge. Students can remember these instruments and equipment parts faster; at the same time also can better improve their structure, dissemblance, installation and operation ability of all kinds of instruments and equipment [6]. In addition, the instruments and equipment structure and working principle of the important components independent components which cannot be observed in real machine training experience, with rich media technology, can carry on realistic simulation so as to provide more practice opportunities for students.

B. Vocational education teaching mode innovation

A key link in improving teaching quality and teaching effect is to let students move eye observation, operate, think, and express themselves. In rich media environment, teaching model reform of vocational education need to be further deepened. In future teaching, teachers should stimulate students' study enthusiasm, improve students' participation in classroom teaching process as a starting point, and strengthen the optimized combination research and exploration of multimedia technology and teaching process optimization ways, guide students the steps of acquiring knowledge and exploring process. Make them master knowledge and improve practice ability, and at the same time better grasp professional skills so that the teaching model can be more perfect and promote the development of students [7]. In addition, in the practice of teaching, teachers should pay attention to strengthening the interaction with students, change traditional teacher-centered teaching ideas, and build teaching mode with students as the main body in order to adhere to the principle of education teaching, respect students' individual difference, and effectively promote teaching pattern reform [8]. Of course, teachers should correctly understand that advanced technology is just an auxiliary means of teaching, so teachers' individual role also cannot be ignored. In teaching practice, teachers should according to actual condition, combined with its own characteristics, select the most suitable multimedia technology, in order to improve teaching quality and teaching effect. The pursuit of pure beautiful, novel and ignore usefulness is not desirable. 


\section{Conclusion}

Overall, rich media used in vocational education teaching reform has a positive role, which can not only provide students with rich information platform for the public to learn, at the same time can also create more suitable learning environment for students development, so that the students can have more freedom to grasp and accept knowledge. In addition, it is important to note that when students are gaining and disseminating knowledge, we should strengthen the feedback of information, thereby promote self recognition with not too much dependence on multimedia technology.

\section{References}

[1] Zhang Wenchang. The application and reflection of multimedia in secondary vocational fine arts teaching [J]. Journal of Henan Agriculture, 2013, (16) : 29 - 30.

[2] Huang Xiang. Vocational education "Fully Digital Multimedia Teaching Method" investigation [J]. Computer Knowledge and Technology, 2013, (24) : 5522-5523.

[3] Song Zhenzhen. The application of multimedia in vocational education Chinese teaching[J]. Journal of China, 2013, (11) : 247-247.

[4] Qian Xiaorong. Higher vocational education development inquiry in multimedia era [J]. Journal of News Front, 2014, 11:213-214.

[5] Zhi Lin, Zhu Yunpeng. Color reform in art vocational education in the perspective of multimedia technology application [J]. Journal of Vocational Education BBS, 2013, (27) : 70-71.

[6] Li Xiang. Introduction to the problems and countermeasures existing in multimedia teaching in vocational education [J]. Journal of Industry and Information Technology Education, 2014, (7) : 4447.

[7] Zhao Xiaodong. Problems and countermeasures in the application of multimedia technology in teaching [J]. Journal of Henan Forestry Science and Technology, 2013 (2) : 43-44.

[8] Zhao Zheng, Zhang Xianzhi. The realization form of media literacy education in colleges and universities under new media environment [J]. Journal of News Front, 2014, (8) : 137-138. 